\title{
A Simulation Study of Drying Chamber for Marine Product
}

\section{Mohd Afzanizam Mohd Rosli ${ }^{1,2 *}$, Hiew Sit Jing ${ }^{1}$, Nur Izzati Mohd Azhar ${ }^{1}$, Maidi Saputra $^{3}$, Sulaiman Ali ${ }^{3}$}

\author{
${ }^{1}$ Fakulti Kejuruteraan Mekanikal, \\ Universiti Teknikal Malaysia Melaka, Hang Tuah Jaya, 76100 Durian Tunggal, Melaka, MALAYSIA \\ ${ }^{2}$ Centre for Advanced Research on Energy, \\ Universiti Teknikal Malaysia Melaka, Hang Tuah Jaya, 76100 Durian Tunggal, Melaka, MALAYSIA \\ ${ }^{2}$ Teuku Umar University, Meulaboh, Aceh, INDONESIA \\ *Corresponding Author
}

DOI: https://doi.org/10.30880/ijie.2021.13.06.005

Received 7 April 2020; Accepted 30 May 2021;13 Available online 31 August 2021

\begin{abstract}
Drying chamber is a drying application for agriculture product to produce high quality and hygiene product. The purpose of this paper is to propose best configuration trays arrangement in drying chamber for better distribution of velocity and temperature. Therefore, five configurations of trays are analyzed to obtain the best performance of uniformity air flow distribution within drying chamber. CFD simulation studied the uniform air flow in the drying chamber in steady state condition. A validation is performed by comparing the data obtained from the literature review CFD simulation to ensure the methodology is correct. Then, the drying chamber with different trays arrangements are simulated using CFD simulations to obtain velocity and temperature distributions at nine plotted points on trays. From the results obtained, it concluded that design (A) and (D) are selected as the best designs for uniformity because there is less discrepancy for each point contributed the more uniformity of distribution.
\end{abstract}

Kevwords: Drving chamber, Computational Fluid Dynamics (CFD) simulation, uniformity distribution

\section{Introduction}

Drying also is defined as moisture/water removal process through evaporation from a solid/ semi-solid/ liquid [1-4]. The purpose of drying process is to reduce the cost for transportation and storage capacity while preserving the freshness of the products [5]. Hence, natural drying such as open sun drying has some limitations which is not suited and effective to all regions due to the condition is not conducive and limited caused adverse weather [6]. This is caused low quality of product. Therefore, there are a few types of industrial dryers introduced in drying industries. The most famous application in drying is developed drying chamber [7, 8]. The main problem in applied this application is non-uniformity of end product [9-11]. This non-uniformity contributed to the low quality of products. Uniform air flow distribution in the chamber is a benchmark of a good drying chamber to ensure uniform drying effect on the product [12, 13]. Uniform air flow distribution is an important factor in improving the homogeneity of the product while increasing the efficiency of a drying chamber. Alternate arrangement of tray is a method used by many researchers to serve this purpose as the all the trays could be exposed directly to the drying air.

Basically, the parameters that most affected drying air are temperature and velocity $[14,15]$. In order to predict the temperature and velocity distribution in the chamber, CFD is utilized. CFD simulation is used in order to cut the budgets, difficult and took a long period of time consuming. CFD simulation also abled to calculate and solve the equations such as conservation of energy, momentum, and mass to predict the distribution of temperature and homogeneity of end dried products [11]. Generally, air velocity for drying process is in the range of $1.5 \mathrm{~m} / \mathrm{s}$ to $3 \mathrm{~m} / \mathrm{s}$. However, factors of moisture 
content of the product also affect the air velocity range. When the air temperature is raised, the evaporation rate from the product will also be increased. Hence, the capacity of water vapor become larger.

Misha et al., [12] has developed a novel arrangement of dryer tray for application of agricultural product to predict drying uniformity by using CFD simulation. Temperature, velocity profile, and streamline profile on each tray are the main factors for analyzing the uniformity. From the simulation result, it is found that the upper tray has the highest average air velocity due to its position which is closest to the inlet and outlet.

The objective of this study is to utilize CFD to; (i) analyze the best temperature distribution in the drying chamber (ii) to investigate the best velocity distribution, and (iii) to propose the best configuration of trays using CFD simulation.

\subsection{CFD Modelling}

The drying chamber is designed by consists of three trays that arranged at the different level as a flow domain. This flow domain was in symmetrical 2D. 2D approach is chosen rather than the three dimensions due to the high requirement of computer resource. The model of chamber has been model by Ansys Fluent 16.1.

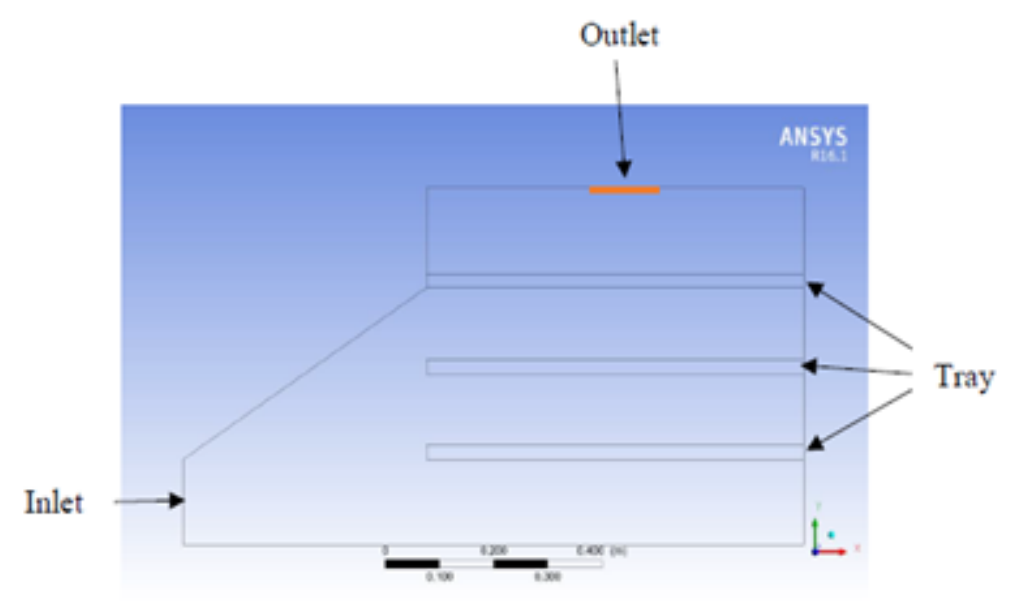

Fig. 1 - Drying chamber

The chamber geometry is measured at $1.15 \mathrm{~m}(\mathrm{~W}) \times 0.625 \mathrm{~m}(\mathrm{H})$ while the thickness of the tray is $0.025 \mathrm{~m}$. Fig. 1 shows the drying chamber geometry. There are five designs of drying chamber with different configurations of trays as shown in Fig. 2. The purpose of these designs is to find out the effect between configurations of trays on the performance of velocity and temperature distribution in the chamber. The best velocity and temperature distribution are determined among these five designs as the best design for drying.

\subsection{Basic Governing Equations for CFD Simulation}

The conservation of energy, momentum, and mass for drying air results in the energy, Navier-Stokes, and continuity equation respectively [16]. Turbulent flow model is used in this study. Following equations are solved in CFD:

Continuity equation:

$\frac{\partial \rho}{\partial t}+\nabla \cdot(\rho \vec{v})=0$

Momentum conservation equations:

$\frac{\partial}{\partial t}(\rho \vec{v})+\nabla \cdot(\rho \vec{v} \vec{v})=-\nabla \mathrm{p}+\nabla \cdot(\overrightarrow{\tau)}+p \vec{g}+\vec{F}$

Energy conservation equation:

$\frac{\partial}{\partial t}(\rho E)+\nabla \cdot(\vec{v}(\rho E+p))=\nabla \cdot\left(k_{e f f} \nabla T\right)+S_{h}$ 


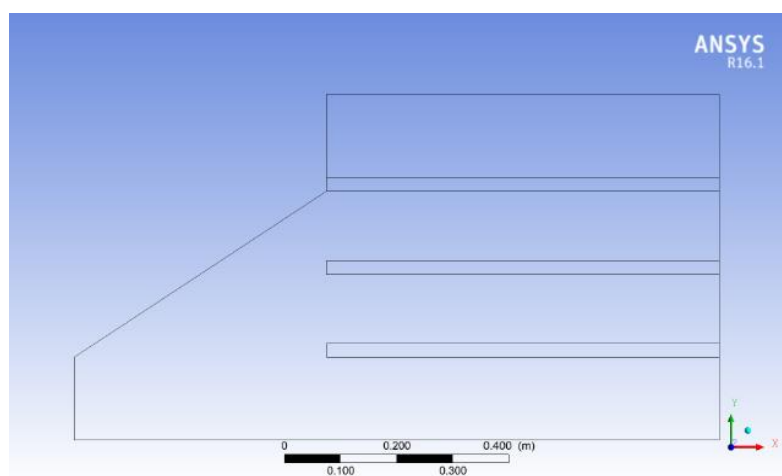

(a) Design A

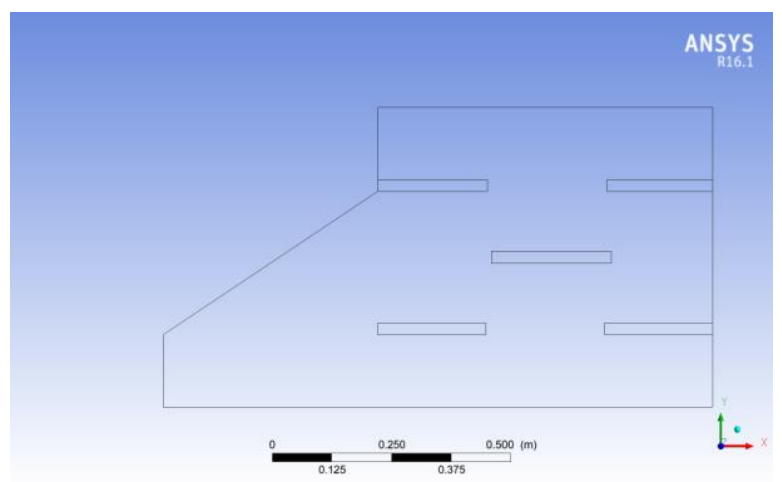

(c) Design C

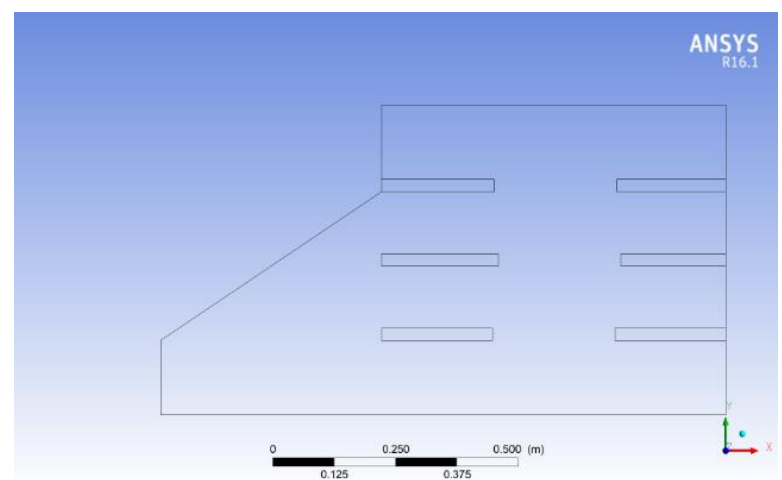

(b) Design B

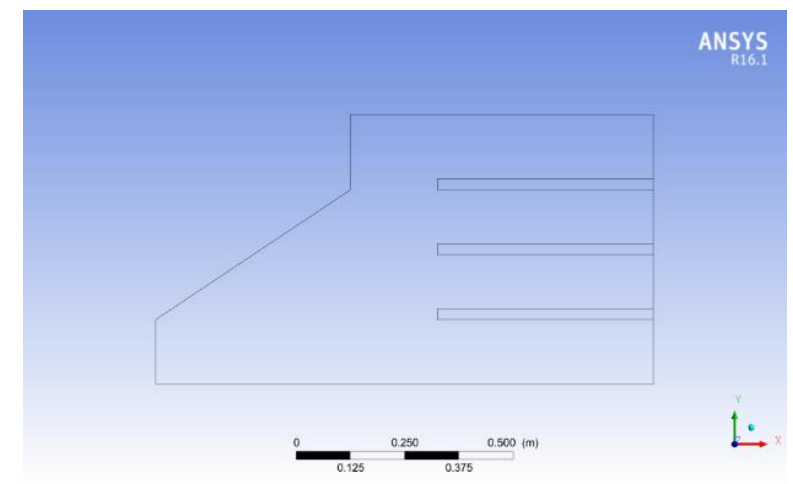

(d) Design D

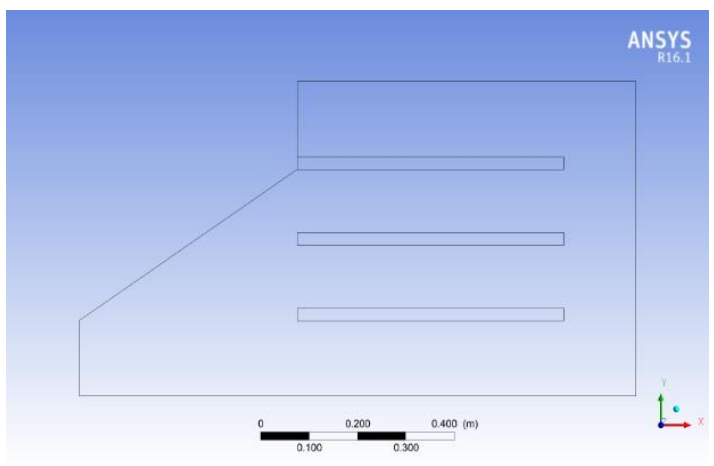

(e) Design E

Fig. 2 - Various designs (Design A - E) of drying chamber with different configurations of trays

\subsection{Simulation}

In this study, ANSYS Fluent 16 was used as a simulation tool to simulate and predict the air flow velocity and temperature distribution in the chamber. This software is able to solve those governing equations (1), (2) and (3) in unstructured tetrahedral grid with number of nodes is 3630 whiles number of elements is 7008. This ANSYS Fluent 16.1 was functionally used method of numerical finite volume [3] for solving all the equations. Standard k-e turbulence model was applied in steady state conditions. At the inlet, a heater was installed as a heat source for the chamber with temperature at $40{ }^{\circ} \mathrm{C}$. Air velocity inlet was set up as $3 \mathrm{~m} / \mathrm{s}$ into the drying chamber for all the cases. At the exhaust, the gauge pressure was assumed to be 0 . The density, specific heat, and thermal conductivity of the drying chamber are 1.225 $\mathrm{kg} / \mathrm{m}^{3}, 1006.43 \mathrm{~J} / \mathrm{kg} . \mathrm{K}$ and $0.0242 \mathrm{~W} / \mathrm{mK}$ respectively. 


\section{Results and Discussion}

\subsection{Result Validation}

In order to validate the simulation result, a comparison between result and experiment data obtained from the literature study was performed. The purpose of this validation to ensure that the steps and properties used for the drying is corrected. By fitting both experimental and simulation drying curves in the graph as shown in Fig. 3, the variation between these results could be analyzed. Fig. 4 shows the correlations between the experimental data from the literature and simulation data obtained.

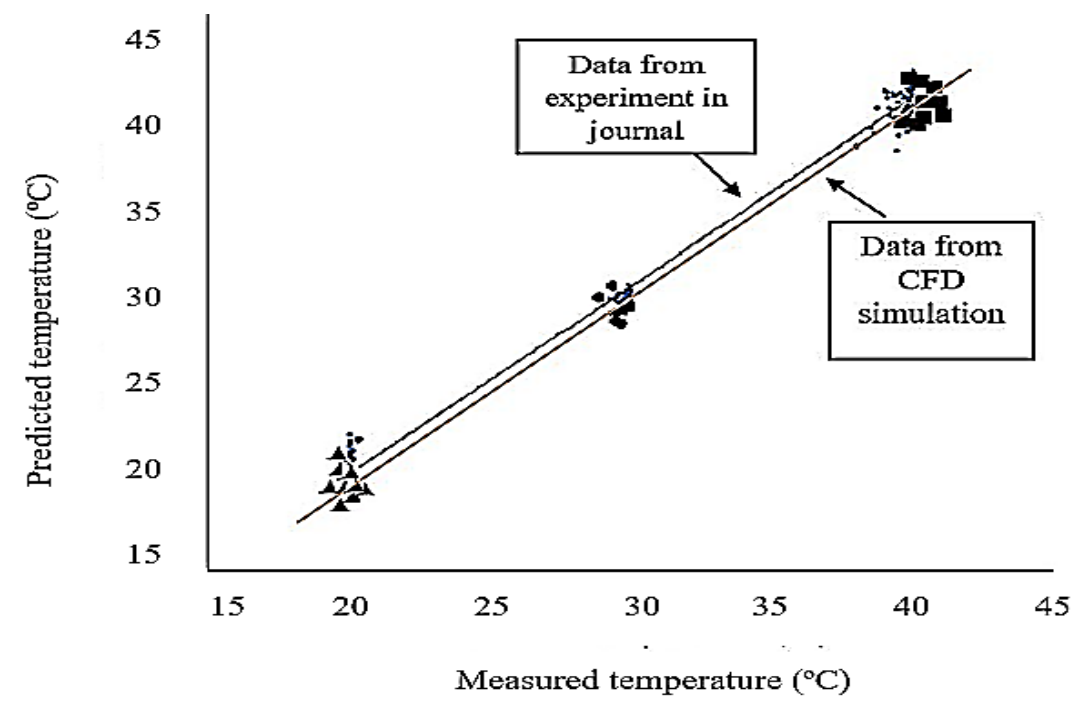

Fig. 3 - Correlation of the simulation results with the experimental data on drying air temperature

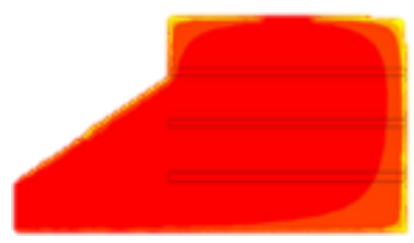

(a)

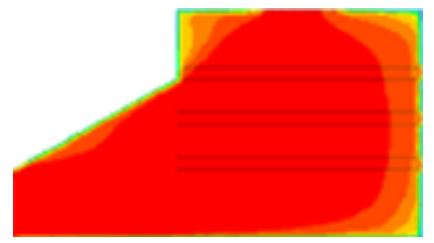

(b)

Fig. 4 - The contour for temperature profiles within drying chamber (a) Results of CFD simulation; (b) Results of CFD simulation from the literature review

\subsection{Air flow Simulation Predictions}

The steady state simulation was performed to solve the energy, momentum, continuity, turbulence dissipation rate, and turbulent kinetic energy equation. In this study, the drying air flow velocity distribution within the drying chamber was done in two-dimensional in symmetrical domain. Based on the Fig. 5, the simulation for vector profiles illustrate that Design A and D have the best uniform air flow distribution. However, design B and C are the poorest of tray configurations for this shape. It can be concluded based on the vector profiles of air flow from the CFD simulation.

Based on the vector profile, it can be concluded that at area closer to the inlet and outlet zones, the air flow velocity is higher. Therefore, the distribution of air flow velocity distributed differently through the trays depends on it levels of arrangement. Basically, the trays near to the inlet and outlet zones will get higher air velocity in average. The results of simulation for the predicted velocity distribution on nine different points for all the designs are shown in Fig. 6 . Although design (D) shows that at the point 3,6 and 9 are highest values than others points caused no trays located at that placed. So that, there are no resistance in distribution of velocity in the chamber to the outlet. All the trays are set up in porous media in order to improve the uniformity of distribution. The average of velocity at the point 9 is the poorest point of velocity distribution. This is because that point is far from inlet and outlet. Therefore, that zone is the lowest zone that received air flow velocity and poor performance of drying process. 


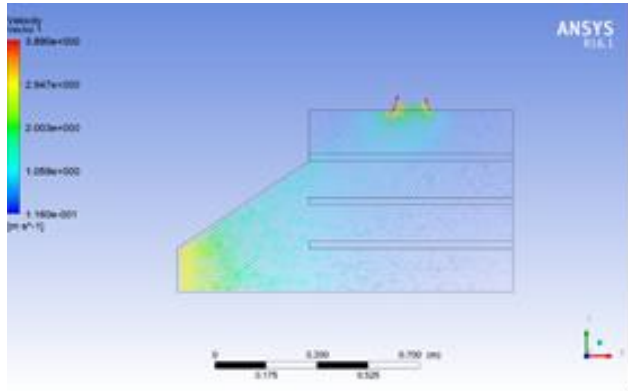

(a) Design A

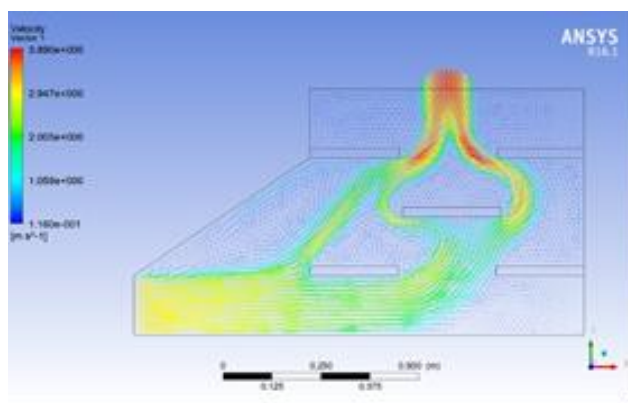

(c) Design C

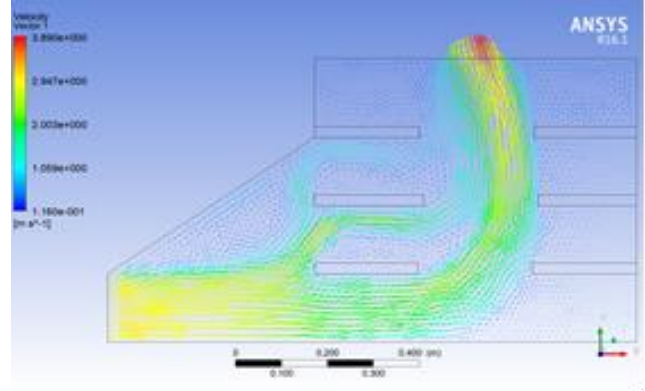

(b) Design B

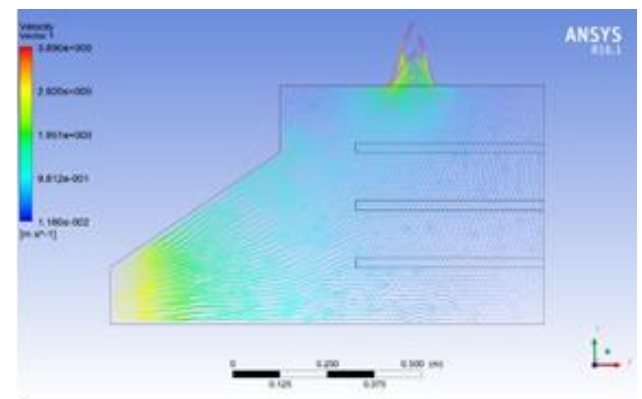

(d) Design D

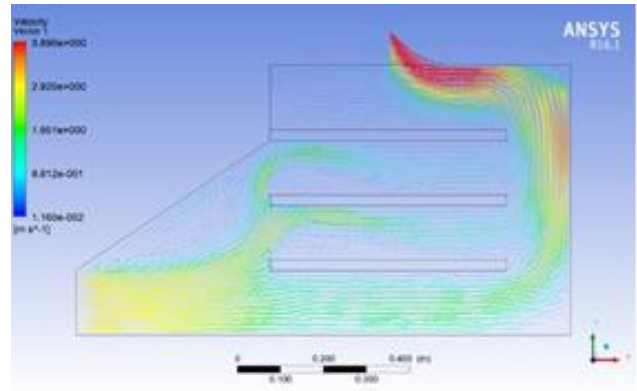

(e) Design E

Fig. 5 - Design of drying chamber for five variation configurations of trays and vector profiles of air flow velocity distribution using CFD simulation

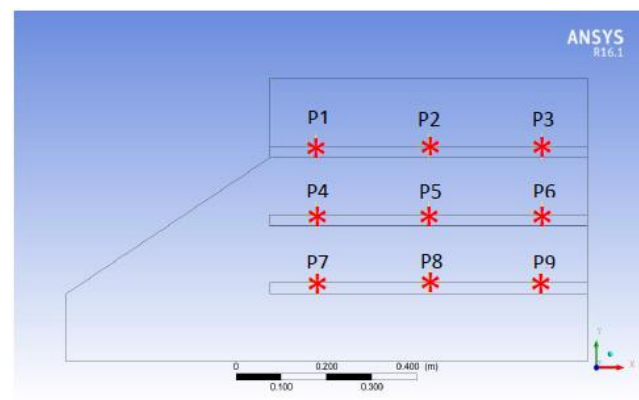

Fig. 6 - Nine measured points on the trays of drying chamber

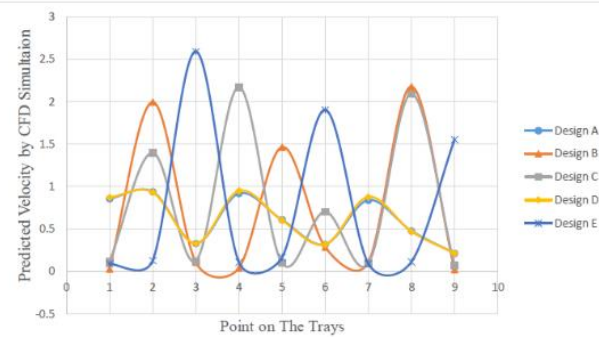

Fig. 7 - Predicted air velocity by CFD simulation against nine points located on trays for each design 
As shown in Fig. 7, Design A and D shows a more uniform of air velocity distributions compared to other designs. The lines graph on Design A and D are not fluctuating as much as like in the other design. Thus, they are able to achieve uniform air velocity distribution with average temperature $0.612 \mathrm{~m} / \mathrm{s}$ and $0.618 \mathrm{~m} / \mathrm{s}$.

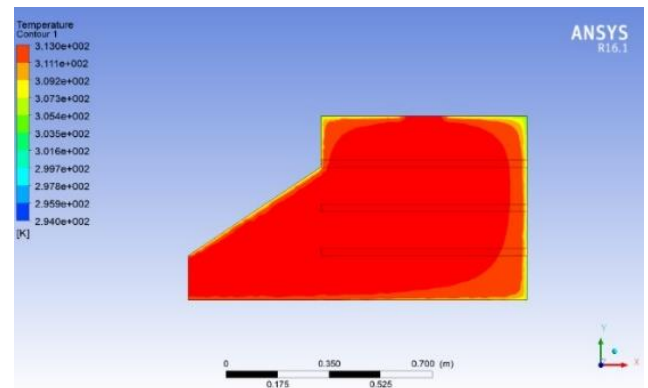

(a) Design A

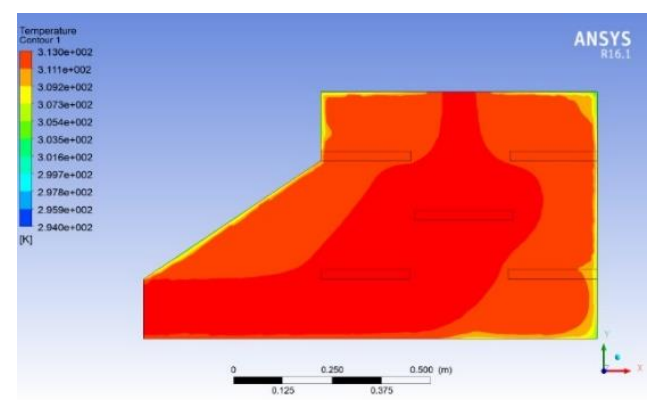

(c) Design C

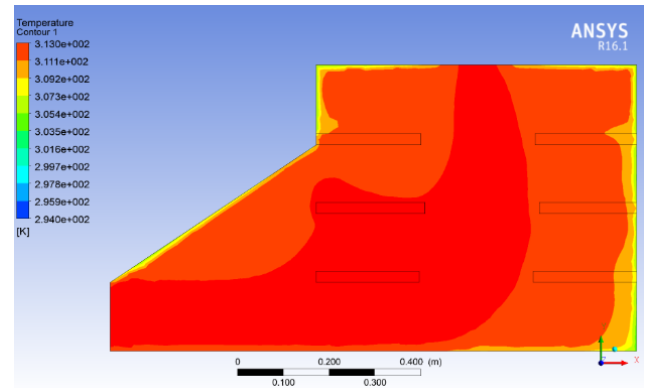

(b) Design B

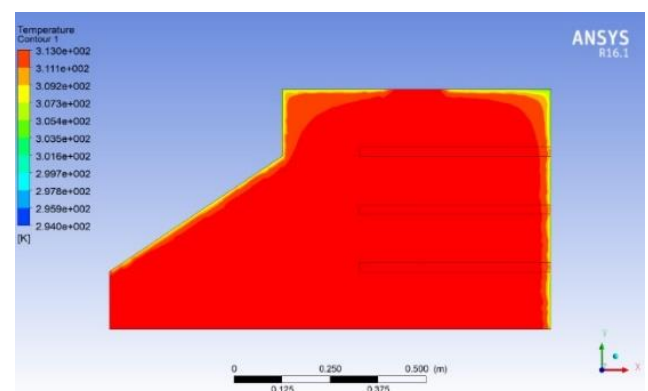

(d) Design D

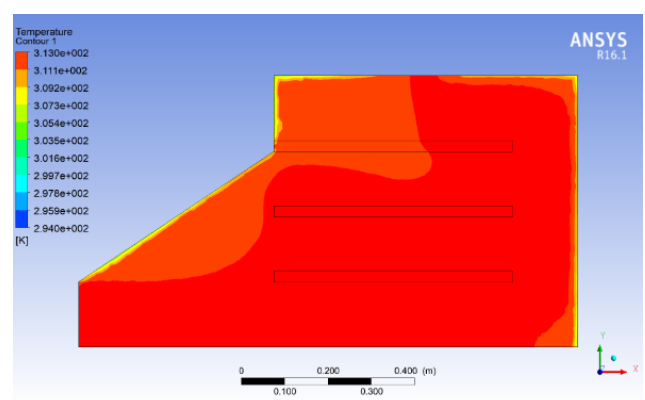

(e) Design $\mathrm{E}$

Fig. 8 - Design of drying chamber for five variation configurations of trays and temperature profiles of air flow velocity distribution using CFD simulation

\subsection{Temperature Distribution}

Firstly, the hot air temperature from the inlet was set as $40{ }^{\circ} \mathrm{C}$ and operating temperature is set up as $44^{\circ} \mathrm{C}$. Based on the contour profile of temperature distribution for the variation of trays configuration in Fig. 8, temperature distribution within drying chamber for all the designs are more or less a similar trend. However, from the results CFD simulation in Fig. 8 of contour profile shows that the best performance of temperature distribution assessed by design A and D. This is because the temperature distribution profiles for both designs distributed similar evenly for each tray. Based on the results obtained for all the configurations, it displayed that changing either the geometrical shape of drying chamber with variation of tray arrangement only have a little bit influence to the temperature distribution compared to the velocity distribution. Fig. 9 shows the graph of temperature distribution in the drying chambers. Design A and D show a more uniform temperature distribution. 


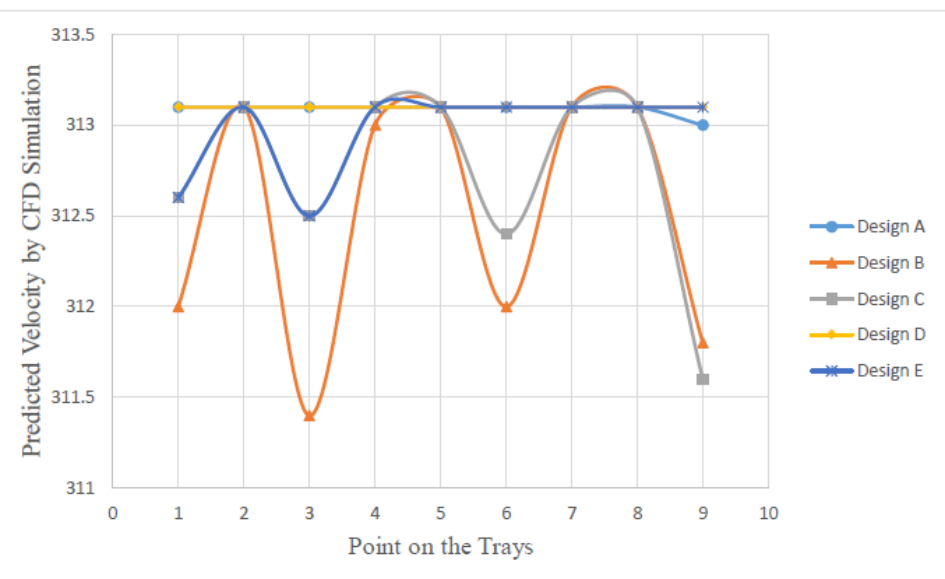

Fig. 9 - Predicted temperature by CFD simulation against nine points located on trays for each design

\section{Conclusion}

Drying performance can be improved by good uniformity of temperature distribution and air velocity in the drying chamber. CFD simulation is the best software in order to predict the velocity and air flow distribution based on the configurations of trays without consuming a lot of time to run the experiment and needed high cost. From the simulation result, it shows that Design A and D are the best performance in term uniformity air flow and temperature distribution. The results also have been compared and validated with experimental data from publish journal as references. Hence, there are correlation between configurations of trays and uniformity distribution as the uniformity distribution is significance in this industry in order to produce a high quality product. As future work, the CFD simulations should be conducted in the form of 3D to obtain a more accurate results that display the real situation of drying chamber. Besides that, transient simulation should be conducted to measure the drying time needed for the drying process

\section{Acknowledgement}

The authors would like to express their gratitude towards Applied Solar Energy Laboratory, Fakulti Kejuruteraan Mekanikal, and Centre for Advance Research on Energy of Universiti Teknikal Malaysia Melaka for providing facilities and support to successfully conducting this research.

\section{References}

[1] Fuente-blanco, S. De and Sarabia, E. R. De (2006). Food drying process by power ultrasound. Ultrasonics, 44, $523-$ 527

[2] Arun S. Mujumdar (1995). Handbook of Industrial Drying ( Vol. 1). Marcel Dekker Inc., New York

[3] Arina M.N., Sohif M., Mohd H.R., (2018). CFD Simulation of temperature and air flow distribution inside industrial scale solar dryer. Journal of Advanced Research in Fluid Mechanics and Thermal Sciences, 45, Issues 1, 156-164

[4] Pravin M.G., Amit S.D., Ranjit C.B., Sagar C.P., Vishal G.P. (2017). Design and construction of solar dryer for drying agricultural products. International Research Journal of Engineering and Technology, Vol.4, No.3, 19461951

[5] Misha, S., S. Mat, M. H. Ruslan, K. Sopian, E. Salleh, and M. A. M. Rosli. (2014). Performance test of solar assisted solid desiccant dryer, 8th WSEAS International Conference on Renewable Energy Sources (RES'14)

[6] William L. Kerr (2013). Handbook of farm, dairy and food machinery engineering. Food drying and evaporation processing operations

[7] Y. Amanlou and A. Zomorodian (2010). Applying CFD for designing a new fruit cabinet dryer. Journal of Food Engineering, vol. 101, no. 1, 8-15

[8] S. Misha, A. Alqadhi, M. A. M. Rosli, and A. A. Yusof (2018). Experimental investigation on indirect, natural and forced convection mixed mode solar dryer. International Journal of Mechanical and Mechatronics Engineering, vol. 18 , no. 2, 87-96

[9] Adams, R.L., Thompson, J.F. (1985). Improving drying uniformity in concurrent flow tunnel dehydrators. Transactions of ASAE, 28 (3), 890-892

[10] Mathioulakis, E., Karathanos, V.T,Belessiotis, V.G. (1998). Simulation of air movement in a dryer by computational fluid dynamics: application for the drying of fruits. Journal of Food Engineering, 3, 183-200

[11] Mirade, P.S. (2003). Prediction of the air velocity field in modern meat dryers using unsteady computational fluid dynamics (CFD) models. Journal of Food Engineering, 60, 41-48

[12] Misha, S., Mat, S., Ruslan, M.H., Sopian, K. and Salleh, E. (2013). The prediction of drying uniformity in tray dryer 
system using CFD simulation. International Journal of Machine Learning and Computing, 3(5), 419

[13] Azhar, Nur Izzati Mohd, Mohd Afzanizam Mohd Rosli, Ahmad Syakir Ghazali, and Hiew Sit Jing (2019). Simulation study of drying chamber for marine product, Proceedings of Mechanical Engineering Research Day 2019, 358-359

[14] Mulet, A., Berna, A., Borras, M., Pinaga, F. (1987). Effect of air flow rate on carrot drying. Drying Technology, 5 (2), 245-258

[15] Karathanos, V.T., Belessiotis, V.G. (1997). Sun and artificial air drying kinetics of some agricultural products. Journal of Food Engineering, 31 (1), 35-46

[16] O. Yongson, I.A. Badruddin, Z.A. Zainal and P.A. Aswatha Narayana (2007). Airflow analysis in an air conditioning room. Building and Environment, Vol. 42, 1531-1537 